\title{
A ORIGEM COMO FORMA DE SUPERAÇÃO DA GUERRA COMO CATÁSTROFE, EM SE O PASSADO NÃO TIVESSE ASAS, DE PEPETELA
}

\author{
ORIGIN AS A WAY OF OVERCOMING WAR AS A CATASTROPHE, IN SE O \\ PASSADO NÃO TIVESSE ASAS, BY PEPETELA
}

Recebido: 13/01/2021

Aprovado: $17 / 05 / 2021$

Publicado: $30 / 07 / 2021$

DOI: $10.18817 /$ rlj.v5i01.2460

\author{
Adriano Guedes Carneiro ${ }^{1}$ \\ https://orcid.org/0000-0002-5830-5128
}

\begin{abstract}
Resumo: O presente artigo tem por objetivo demonstrar como o conceito de Origem - Ursprung conforme preconizado por Walter Benjamin foi utilizado no romance Se o passado não tivesse asas, do escritor angolano Pepetela, como forma para superar a guerra como catástrofe. Pepetela é o mais importante escritor angolano e ganhador do Prêmio Camões em 1997. Angola foi colonizada por Portugal. Tornou-se independente, após 14 anos de conflito. A independência lançou o país na guerra civil, entre MPLA, UNITA e FNLA, que durou até 1990. No entanto, a guerra foi retomada em 1992 e só se extinguiu em 2002. No romance, Himba é a menina que sobrevive à explosão do caminhão que levava sua família para Luanda. Mantém-se viva, graças aos restos de comida dos restaurantes locais jogados num contentor de lixo. Em 2002, ela constata a morte de toda a sua família, após visitar o seu antigo município natal. Resolve alterar sua identidade, passando a se chamar Sofia Moreira. Neste ato, entendo estar-se realizando o Ursprung. Ela começa a trabalhar em um restaurante. Torna-se sócia e depois proprietária do estabelecimento. Para tanto, subtrai os direitos de Ezequiel, o filho deficiente da antiga dona do restaurante. Ao se tornar Sofia, ela deixa para trás a vítima e se torna a predadora, sobrevivendo à guerra e podendo superar finalmente o conflito civil. Usamos a contribuição teórica de Walter Benjamin, Kwane Anthony Appiah, Stuart Hall, Michael Löwy, Jeanne Marie Gagnebin, Georges Didi-Huberman e Renata Flávia da Silva.
\end{abstract}

Palavras-chave: Se o passado não tivesse asas. Pepetela. Origem. Guerra. Catástrofe.

\begin{abstract}
This article aims to demonstrate how the concept of Origin - Ursprung - as advocated by Walter Benjamin was used in the novel Se o passado não tivesse asas, by the Angolan writer Pepetela, as a way to overcome the war as a catastrophe. Pepetela is the most important Angolan writer and winner of the Camões Prize in 1997. Angola was colonized by Portugal. It became independent after 14 years of conflict. Independence launched the country into the civil war, between MPLA, UNITA and FNLA, which lasted until 1990. However, the war was resumed in 1992 and was only extinguished in 2002. In the novel, Himba is the girl who survives the truck explosion who was taking his family to Luanda. She stays alive, thanks to the remains of food from local restaurants thrown in a garbage container. In 2002, she witnesses the death of her entire family, after visiting her former home town. She decides to change her identity, changing her name to Sofia Moreira. In this act, I understand that Ursprung is taking place. She starts working at a restaurant. She becomes a partner and then owner of the establishment. To do so, she subtracts the rights of Ezequiel, the disabled son of the former owner of the restaurant. Upon becoming Sofia, she leaves the victim behind and becomes the predator, surviving the war and being able to finally overcome the civil conflict. We used the theoretical contribution of Walter Benjamin, Kwane Anthony Appiah, Stuart Hall, Michael Löwy, Jeanne Marie Gagnebin, Georges Didi-Huberman and Renata Flávia da Silva.
\end{abstract}

Key words: Se o passado não tivesse asas. Pepetela. Origin. War. Catastrophe.

\footnotetext{
${ }_{1}^{1}$ Mestre em Estudos Literários pela Universidade Federal Fluminense, na subárea de Literatura Portuguesa e Literaturas Africanas de Língua Portuguesa pela Universidade Federal Fluminense. Graduação em Letras pela Universidade Federal Fluminense. E-mail: adrianoguedes.carneiro@hotmail.com
} 
A Origem - o Ursprung - tem importância fundamental na obra de Walter Benjamin. Na tese XIV podemos observar todo o vigor do conceito pois ele preconiza que a história deve ser o objeto de uma construção cujo lugar não será formado pelo tempo homogêneo e vazio, mas "por aquele saturado pelo tempo-de-agora (Jetztzeit). Assim, a antiga Roma era, para Robespierre, um passado carregado de tempo-deagora, passado que ele fazia explodir do contínuo da história" (BENJAMIN, 2016 b, p. 249). A Revolução Francesa compreendeu-se como uma Roma que havia retornado, para Benjamin.

Já em 1928, em A origem do drama trágico alemão, Benjamin, segundo Georges Didi-Huberman, proporá colocar a questão da história em termos de origem, buscando, "através da imagem dinâmica e constantemente presente em cada objeto histórico, do turbilhão (que pode surgir a qualquer momento, imprevisivelmente, na correnteza do rio" (DIDI-HUBERMAN, 2019, p. 95). Por isso escreve Benjamin:

\begin{abstract}
A origem (Ursprung), ainda que seja uma categoria inteiramente histórica (historische Kategorie), não tem nada em comum com a gênese (Entstehung) das coisas. A origem não designa o devir daquilo que nasceu, mas sim do que está nascendo no devir e no declínio. A origem é um turbilhão no rio do devir (...) Ela pede para ser reconhecida, de um lado como uma restauração, uma restituição, de outro, como algo que, por isso mesmo, está inacabado, sempre aberto (Unvollendetes, Unabgeschlossenes) (BENJAMIN apud DIDIHUBERMAN, 2019, p. 96).
\end{abstract}

Portanto, podemos concluir com Didi-Huberman, ainda que a imediata preocupação dele seja a história da arte, mas no sentido da história mesmo que se ela tiver a capacidade de criar "'novos objetos originários' será (...) uma história [da arte] capaz de criar turbilhões, fraturas rasgos no próprio saber que ela tem por tarefa produzir" (DIDI-HUBERMAN, 2019, p. 96). E essa foi justamente a estratégia literária posta em ação pelo escritor angolano Pepetela com relação à sua personagem Himba que se transforma em Sofia, no romance Se o passado não tivesse asas (2016).

Pepetela é o grande nome da literatura angolana, forjado na luta pela independência ${ }^{2}$ e na formação do novo país africano. É um contador de estórias, uma espécie de griot moderno, na acepção mais elevada que este termo possa receber, pois foram eles, nas sociedades bantu, na maioria ágrafas, "os responsáveis por registrar e recontar, quando necessário, informações valiosas e historicamente

2 Pepetela integrou o Estado-Maior da Frente Centro do MPLA - Movimento Popular para a Libertação de Angola. Integrou a primeira delegação do MPLA a chegar a Luanda, em 1974. 
relevantes com precisão3" (FOURSHEY et al, 2019, p. 79). Entre uma gama de atividades e competências dentro do grupo comunal, eles ofereciam coesão, senso de pertencimento e explicação sobre as questões fundamentais que os envolviam, mantendo vivas as chamas da tradição. Tal como, guardadas as devidas proporções, faz Pepetela em sua escrita, que tem o compromisso permanente com o processo de construção de Angola.

Em Se o passado não tivesse asas é contada a estória de Himba/Sofia. A ação transcorre concomitantemente em dois períodos de tempo distintos da vida da personagem: em 1995, quando Himba tem 13 anos e 2012, quando Sofia tem 30. Ao longo do romance, as estórias são trabalhadas como se fossem distintas. Somente, nas últimas páginas do livro, é que temos a confirmação do que já desconfiávamos durante parte da leitura: Himba e Sofia são a mesma pessoa; assim como Kassule e Diego o são. Primeiro em "E o primeiro nome seria Sofia, como a irmã perdida de Kassule" (PEPETELA, 2017, p. 342) e a seguir: "Afinal continuas a ser minha irmã. Não me peças mais do que isso, Himba" (PEPETELA, 2017, p. 355) - diz Diego para Sofia, revelando a mudança das identidades.

Acompanha-se a estória de Himba e logo a seguir a de Sofia: numa parte do capítulo encontramos a menina, e algumas páginas mais à frente, a mulher. A primeira é a única sobrevivente da explosão do veículo em que sua família viajava para fugir dos conflitos armados que tinham chegado à sua terra natal. Vinha, desde o Huambo, no Planalto Central, com destino a Luanda. Sozinha, após o trágico acontecimento, com o auxílio de soldados, consegue chegar até a capital do país. Desamparada e abandonada, vive uma verdadeira guerra particular pela sobrevivência. Conhece Kassule, um menino de 10 anos, que perdeu a perna na explosão de uma mina terrestre. Mina esta, que também vitimou e foi fatal para sua mãe, tornando-o órfão. Ele passa a ser o seu melhor amigo, companheiro e verdadeiro irmão inseparável. Os dois lutam dia, após dia, tentando sobreviver, na llha de Luanda ${ }^{4}$, alimentando-se com os restos de comida de restaurantes da região, que são jogados num contentor de lixo. As crianças se alimentam de lixo orgânico, o qual é disputado por vários meninos e

3 Joseph C. Miller, em Poder político e parentesco: Os antigos estados Mbundu em Angola (1976) nos fala a respeito dos Imbangala, população bantu, em que os seus griots se utilizam dos malunda para recontar a história. No malunda há um fundo histórico verdadeiro e fixo, enquanto o baka a musendo, o historiador, tem liberdade na elaboração dos pormenores da história.

4 Também conhecida como llha do Cabo. Extensão de terra que separa a capital Luanda do Oceano Atlântico. 
meninas abandonados e órfãos da guerra. Além disso, Himba sofre todo o tipo de violência física e psicológica, até ser violada sexualmente - num estupro coletivo por jovens de um dos bandos que habitavam a ilha.

Já Sofia Moreira trabalha em um restaurante, na cidade de Luanda, que vai se tornando um dos favoritos da classe social mais rica. Sobretudo, passa a receber a frequência permanente dos "príncipes", os jovens filhos dos ministros, generais e empresários angolanos. A irmã de Diego trava relacionamento com essas pessoas. Parece promissor, mas é apenas superficial e em razão do serviço que lhes oferece. Pois ela possui um talento culinário fenomenal, cujo segredo parece ser a utilização de ervas e temperos incomuns. A amizade com Salomé, por exemplo, não avança, nem as investidas dos pretendentes, Abdias e Kaleb, têm sucesso. Ainda assim, assistimos à sua escalada social, quando se torna sócia e mais tarde única proprietária do estabelecimento.

Parece haver uma dualidade, ou a aparência de dualidade, na forma de construção de alguns elementos que compõem o romance, pois, por exemplo, os dois personagens protagonistas possuem, durante a narrativa, dois nomes: Himba/Sofia e Kassule/Diego. São duas Luandas, a cidade e a ilha. São duas histórias mas que na verdade são uma. Essa dualidade parece o "ser ou não ser" de Angola que, após a Independência também foi duas: a República Popular de Angola, inspirada num ideário socialista e a República de Angola, democracia liberal, sob as regras da economia de mercado.

A independência do país foi proclamada em 11 de novembro de 1975 por Agostinho Neto, líder do MPLA - Movimento Popular para a Libertação de Angola. Esse ato punha fim há, pelo menos, quatorze anos de luta contra a dominação portuguesa. Luta empreendida por esse partido político, além da FNLA - Frente Nacional para Libertação de Angola e da UNITA - União Nacional para a Independência Total de Angola. Finalizava-se o conflito pela independência, porém se iniciava a guerra civil.

O MPLA foi fundado em 1956 e recebeu em suas fileiras o apoio e a adesão de figuras de destaque e respeito no meio político e intelectual, como Mario Pinto de Andrade, ensaísta, poeta e organizador do Caderno de poesia negra de expressão portuguesa (1958) e do poeta Viriato Cruz. Além de Agostinho Neto, também poeta, e que se tornaria a personalidade mais importante do movimento e primeiro presidente 
de Angola até sua morte em 1979. Teve forte apoio da URSS e de Cuba. No Congresso em 1977 adotou a linha de partido marxista-leninista.

A FNLA tinha sua base nas províncias do norte e era formada basicamente pela etnia bakongo. Era anticomunista e seu líder também criou o chamado GRAE ${ }^{5}$, por volta de 1962, em que Jonas Savimbi era o ministro dos negócios estrangeiros. Tentou, em 1975, sem sucesso, avançando desde o norte, tomar Luanda, para frustrar a independência em 11 de novembro, mas foram detidos pelas FAPLA ${ }^{6}$, do MPLA e por fortes efetivos cubanos, na Batalha de Quifangondo, a cerca de $30 \mathrm{~km}$ da capital. A FNLA, neste ataque, teve o apoio do $Z^{2} a^{7}{ }^{7}$ (atual República Democrática do Congo), da África do Sul e o logístico dos EUA. Foram derrotados e alguns dos seus integrantes retornaram ao Zaire e outros se agregaram à UNITA. O líder da FNLA, Holden Roberto, falecido em 2007, só retornaria novamente a Angola em 1992 para disputar as eleições.

A UNITA foi fundada por Jonas Savimbi, em 1966 e era formada em sua maioria pela etnia Ovimbundo, da qual seu fundador provinha. Recebeu inicialmente apoio da China, mas depois também da África do Sul (regime do apartheid) e dos EUA. Proclamaram junto com a FNLA a independência de Angola, no Huambo. Fez a guerra civil contra o MPLA, após 1975. Estabeleceu o acordo de paz, em 31 de maio de 1991, os Acordos de Bicesse ${ }^{8}$, quando houve o fim da República Popular de Angola e do regime socialista. Savimbi disputou a eleição presidencial, em 1992, mas foi derrotado por José Eduardo dos Santos. Não aceitou o resultado, alegando fraude eleitoral, apesar do acompanhamento realizado pela Organização das Nações Unidas e tomou novamente em armas e a guerra civil prosseguiu. A paz só foi novamente conquistada em 2002, após o assassinato do próprio Savimbi e, assinados os novos acordos de paz, os Acordos de Luena. A UNITA hoje é um partido político em Angola., como também o é a FNLA 9 .

5 Governo da República de Angola no Exílio.

6 Forças Armadas Populares de Libertação de Angola.

7 E de seu famigerado líder Mobuto Sese Seko, o assassino do legítimo presidente do Congo Patrick Lumumba.

8 Assinados em Estoril, Portugal, pelo Governo de Angola, representado pelo MPLA, pela UNITA, por Portugal, EUA e Federação Russa, que já havia sucedido à antiga URSS - União das Repúblicas Socialistas Soviéticas.

9 Na Assembleia Nacional de Angola, órgão do poder legislativo, é composta por 220 deputados. Sendo, na atual legislatura, 150 provenientes do MPLA, 51 da UNITA, 16 da Coligação CASA-CE, 2 do PRS e 1 do FNLA. 
Em 1992, com o fim da URSS, a queda do Muro de Berlim e o fim do chamado socialismo real, Angola decidiu "abrir as portas" à chamada democracia liberal de mercado. Pepetela tem escrito muito sobre esse período. Como salienta Rothwell:

\begin{abstract}
A obra de Pepetela fornece uma análise fundamental que nos permite - a partir de um prisma pós-comunista - compreender as continuidades da tripla transição (colonialismo-comunismo-capitalismo). Autor de mais de duas dúzias de relevantes obras de ficção abrangendo as quatro décadas de existência de Angola independente, desde a década de 1990, Pepetela tem vindo a abordar as implicações da queda do Muro de Berlim na nação angolana. Caracterizações recorrentes nos seus romances apontam para a mediocridade pós-comunista, na qual os verdadeiros crentes na justiça social são postos de lado - enquanto os seus discursos são apropriados - e predadores ineptos mas vorazes conquistam proeminência (ROTHWELL, 2019, p. 202).
\end{abstract}

Em Predadores (2005), em outra obra de Pepetela, a personagem Vladimiro Caposso é movida pela ânsia da ganância, de crescimento pessoal. Ele tem pulsão pelo enriquecimento, o maior exemplo de "predador inepto mas voraz", conforme a citação de Rothwell. Inicialmente, no pós-independência, Caposso vai se adaptando, ao modo de vida da sociedade socialista, mas dando o seu "jeitinho", procurando tirar vantagens pessoais de suas posições políticas no partido. Mas o apogeu de suas "atividades gananciosas" ocorrerá realmente no período "pós-comunista". personagem tem alma de candongueiro. Aliás, Pepetela escreve em A geração da utopia (1992), que essa é a nova classe de empresários de Angola: os candongueiros, que viviam do transporte de pedestres, fazendo lotada, no regime anterior.

Rothwell ainda nos diz que, mesmo que "o período comunista de Angola tenha apresentado ruidosas e desconfortáveis semelhanças com as estruturas do poder colonial" (ROTHWELL, 2019, p. 203), o que ele chama de "pós-comunismo" vai encobrir a continuidade política. No centro da arena política, continua o MPLA, que antes defendia o socialismo, alinhado a Moscou, mas agora se apresenta como propagador de uma ideologia "democrática" e liberal. O MPLA fez a transição de um regime socialista para um capitalista, sem abrir mão do poder político, sem deixar de ser governo.

O professor Benjamin Abdala Jr., no ensaio "Fronteiras e identidades no plural: das demarcações políticas aos comunitarismos supranacionais", publicado em Utopias comuns em múltiplas fronteiras (2017), esclarece-nos, abordando uma das crises cíclicas do regime capitalista, que a grande mídia, mesmo "antes do crack financeiro de 2008, naturalizou e, ainda, continua a naturalizar, com menor ênfase, a 
imagem utópica do mundo das finanças: desregulamentação e flexibilidade como modelo para a economia" (ABDALLA JR., 2017, p. 11). Tenta-se a todo custo tornar natural a chamada economia de mercado, dentro da ótica do neoliberalismo, oferecida, principalmente, para as chamadas nações do Terceiro Mundo, como a panaceia que resolveria todos os seus problemas e conflitos. Principalmente, após o início da década de noventa do século passado, tem-se erigido o mercado como uma espécie de novo deus. Mas, o que se tem visto, na verdade, é um empobrecimento generalizado destas nações, com a perda de direitos individuais e coletivos por parte dos cidadãos e trabalhadores, aumento da desigualdade de renda, sucateamento de direitos sociais, como saúde e educação e abandono dos valores de preservação do meio ambiente.

Stuart Hall também nos alerta para esse liberalismo que, mesmo tendo aperfeiçoado algumas grandes ideias, como é o caso da liberdade, igualdade, autonomia ou a democracia, quer se impor de uma forma universalizante (e globalizante), tornando-se hegemônico em todo o mundo, como "a cultura além das culturas" (HALL, 2018, p. 85). Tentam naturalizar também a ideia de que atingimos o apogeu do desenvolvimento humano e social, do evolucionismo. Alguns pensadores, por diversas razões, têm falado mesmo no fim da História ou mesmo da Política ${ }^{10}$

Tudo isso é resultado daquilo que Anthony Appiah bem definiu como: "a incorporação de todas as áreas do mundo até mesmo da antiga vida 'privada', na economia monetária. A modernidade transformou cada um dos elementos do real num letreiro, e o letreiro diz 'vende-se'” (APPIAH, 2014, p. 201). Tudo está à venda na escravidão moderna neoliberal.

Entretanto, Inocência Mata publica, em 1999, um ensaio na Revista Literatura Scripta, cujo título é "Pepetela: um escritor (ainda) em busca da utopia”. A professora santomense da Universidade de Lisboa, e especialista na obra do escritor angolano, registra, como utopia, a postura deste autor em buscar fazer do texto um algo além, pois este não deve ser um fim em si mesmo, mas buscar a reflexão, a mudança, o entendimento. Deve ser crítico. O texto não pode sucumbir à "ditadura da ganância" -

10 Ver a interpretação do final da Fenomenologia do Espírito, de Hegel, por Alexandre Kojéve, em Introduction à la lecture de Hegel (1947), que influenciaram o artigo e depois livro O fim da história (1989), de Francis Fukuyama. E ainda, para o fim da política, O ódio à democracia (2005), de Jacques Rancière. Hans Ulrich Gumbrecht, em Depois de 1945 (2014) fala no fim do conceito de História como o compreendemos hoje. Também precisamos citar sobre o fim da História o livro No fio da navalha, de Danilo Araújo Marques, publicado pela UFMG. O livro é fruto da Tese, que se encontra disponível no banco de teses da universidade. 
para citar a fala da personagem Diego Moreira, em Se o passado não tivesse asas. Essa postura, em relação ao seu texto, é o que aqui chamaremos de ethos de resistência, o comportamento de resistência de Pepetela.

O ganhador do Prêmio Camões de 1997 não tem uma postura neutra e imparcial. Não fica apenas observando as águas do rio da sociedade angolana passarem à sua frente. Ele tem lado, participa, intervém e torce pelo êxito e sucesso. Está inserido no processo de construção da nação. Trabalha para que tudo fique melhor e não quer que nada dê errado. Há a preocupação no seu texto com o entendimento da sua época, mas também a defesa da justiça e pela vitória de um país mais humano, mais justo, menos comprometido com uma espécie de "buganvília política" - para usar uma metáfora baseada em O cão e os caluandas $(1985)^{11}$.

Em mais de um momento, Pepetela tem se posicionado como um socialista, com um olhar muito claro para os vencidos da história. O socialista, numa concepção mais abrangente, será aquele que acredita e trabalha para e pela vitória dos explorados e dos oprimidos. Talvez esta seja a sua verdadeira utopia, a razão do seu ethos de resistência, o algo além a que Pepetela esteja perpetuamente buscando, num campo de ação bem próximo ao de Walter Benjamin e as teses sobre o conceito de história de 1940. Para que as teses se tornassem um instrumento na luta pela emancipação dos explorados e oprimidos em todo o mundo. Podemos parafrasear o título do ensaio de Inocência Mata: "Pepetela: um escritor (ainda) em busca da revolução".

Também na abertura do seu importante livro Fiç̧ão e História na literatura angolana: o caso Pepetela (2010), Inocência Mata nos traz uma citação de Fredric Jameson para quem tudo era social ou histórico, em última instância, político. A obra do criador de O planalto e a estepe (2009) é recheada pela preocupação com questões políticas. Portanto, desconsiderar a dimensão política do texto pepeteliano é tapar os olhos para algo fundamental, porque ele sempre foi um combatente e lutou pelo que acredita e acha correto. Do contrário, por que assinar os seus livros com o pseudônimo que usava nos tempos da guerra de independência12, se não para nos

11 Neste livro, também de autoria de Pepetela, o cão pastor alemão luta contra uma buganvília que se alastra como a corrupção por Angola.

12 Pepetela foi pelo qual ele era conhecido nos tempos da guerra de independência e quer dizer "pestana". Ele participou da Frente centro do MPLA. Foi um dos primeiros a entrar em Luanda, em 1974. Foi Vice-ministro da Educação de Angola, entre 1976-1982. 
dizer que a luta é contínua, só que agora em outras trincheiras? Para o materialistadialético, a luta só terminará com a vitória dos oprimidos.

O título do romance também é muito intrigante. Pois é uma condicional negativa "se o passado não tivesse asas", ou seja, subentende-se que o passado tenha asas, mas se não as tivesse qual seria a diferença? Qual a relação disso com a diegese do livro? Se ele não tivesse asas, então faria sentido sufocá-lo, poderíamos esquecê-lo como mais facilidade? O ter asas tanto pode significar que a todo momento ele estará presente ou que poderá se afastar para longe, pois as asas, sem dúvida, indicam uma velocidade alta, rapidez e tanto servem para se aproximar quanto para se afastar. Não pode passar em vão a relação que pode ser estabelecida com o "Anjo da história", conforme escreve Benjamin, em relação à pintura de Paul Klee, na tese IX. Apesar de longa, transcrevemos todo o texto desta tese:

Há um quadro de Klee intitulado Angelus Novus. Representa um anjo que parece preparar-se para se afastar de qualquer coisa que olha fixamente. Tem os olhos esbugalhados, a boca escancarada e as asas abertas. $O$ anjo da história deve ter esse aspecto. Voltou o rosto para o passado. A cadeia de fatos que aparece diante dos nossos olhos é para ele uma catástrofe sem fim, que incessantemente acumula ruínas sobre ruínas e lhas lança aos pés. Ele gostaria de parar para acordar os mortos e reconstituir, a partir de seus fragmentos, aquilo que foi destruído. Mas do paraíso sopra um vendaval que se enrodilha nas suas asas, e que é tão forte que o anjo já não consegue fechar. Esse vendaval arrasta-o imparavelmente para o futuro, a que ele volta as costas, enquanto o monte de ruínas à sua frente cresce até o céu. Aquilo a que chamamos o progresso é este vendaval (BENJAMIN, 2018, p. 14).

A interpretação da alegoria pode nos trazer alguma informação também sobre as intenções de Pepetela quanto ao título do livro: Se o passado não tivesse asas. Tanto o passado referido no título do livro quanto o Angelus Novus de Benjamin têm asas e ambos, se não representam a história em si, têm uma relação muito forte com ela. Segundo Michael Löwy, o anjo simboliza uma alegoria, pois "seus elementos não têm, fora do papel, o significado que lhes é intencionalmente atribuído pelo autor" (LÖWY, 2020, p. 87). Há pouca relação com o quadro em si, pois Benjamin projetou no mesmo os seus próprios sentimentos e ideias sobre a imagem do artista alemão13. Há uma significativa correspondência na alegoria entre o sagrado e o profano, a teologia e a política, pois elas perpassam todas as imagens evocadas na tese. $O$ correspondente profano da tempestade que sopra do paraíso, como nos diz Löwy, é

13 Paul Klee nasceu na Suíça, mas filho de pai alemão. A nacionalidade alemã é definida pelo sangue e não pelo território onde se nasceu. 
o “progresso, responsável por uma 'catástrofe sem trégua' e por um 'amontoado de escombros que cresce até o céu'”(LÖWY, 2020, p. 89).

Esse "Anjo da história de Angola" está associado a todas as catástrofes, as hecatombes, os massacres que vêm acontecendo desde o colonialismo - a máquina de produzir violência - passando pelas guerras de independência e civil, pelo processo de transformação pelo qual passou o MPLA com a permanência no poder, a corrupção de seus quadros, o neocolonialismo, o neoliberalismo, a exploração econômica, a pauperização da população. É isso a que o título alude: lembremos do passado para não repetirmos indefinidamente os mesmos erros.

No romance, há um momento, no capítulo 16, quando Himba, em 2002 também num ano importante para a história de Angola, pois marca o fim da guerra civil - retornou ao seu município de nascimento, no Huambo. Dali tinha tentado, junto com sua família, em 1995, chegar até Luanda para escaparem à guerra. No romance, identifico esta passagem como o Ursprung de Himba, o momento em que ela retorna a sua origem, conforme preconiza Benjamin. Não é sua gênese, mas um retorno ao seu antigo lar:

\footnotetext{
Kassule não tentou demovê-la da viagem.

$(\ldots)$

Sentada na pedra, recordando os tempos da infância, procurou solução para o início da busca. Ou indago alguém sobre alguém da igreja, deve haver padre ou sacristão, ou vou descobrir a administração, sei, disseram, ainda existe um administrador municipal. É só perguntar onde fica.

(...)

Portanto fomos lá e o camião estava todo queimado. Trouxemos os corpos das pessoas, alguns muito carbonizados, foi demasiado trabalho para pouca gente $(\ldots)$

- Não era. O teu pai foi identificado. Depois te levo ao cemitério improvisado que temos agora. Se quiseres... (PEPETELA, 2017, p. 334-338).
}

Enquanto rememoração individual, as memórias de Himba são Erlebnis. Somente seriam Erfahrung se tivessem a condição da coletividade, como reminiscências de todos, do país, dos oprimidos, de uma classe social. Gagnebin considera essa questão outro tema central na filosofia de Benjamin, pois, no mundo capitalista, há a degradação da Erfahrung, como experiência coletiva, o fim da arte de contar, por exemplo, conforme lemos em "O narrador" (1936), do pensador berlinense; ao passo que há o fortalecimento da Erlebnis, como experiência vivida, característica do indivíduo solitário. 
Gagnebin também escreve a respeito do Ursprung, estabelecendo a relação com esse momento de reminiscência:

Se a origem remete, então, a um passado, isso se dá sempre através da mediação do lembrar ou da leitura dos signos e dos textos, através da rememoração (Eingedenken), categoria-chave da filosofia da história de Benjamin, oriunda, sem dúvida nenhuma, da tradição religiosa judaica (GAGNEBIN, 2013, p. 14).

O Ursprung de Himba coincide com um retorno à origem. Depois desse momento de mônada, ela teve acesso ao seu passado e futuro, sua pré e pós-história. É quando, na volta a Luanda, ela tem a "iluminação" e a superação de si própria. Ela decide trocar de identidade. Deixar a menina da rua, lá atrás, sem carregar o peso de um passado que só Ihe trazia dor e comoção aos outros, para se tornar a irmã de Diego. Começar do zero e ter uma oportunidade maior de conseguir algo em sua vida e de sobreviver com mais facilidade.

Renata Flávia da Silva constata que, em relação à obra de Pepetela, a maturidade de Himba tem o sentido de:

Há entre o romance publicado em 2016 e a crônica intitulada "Meninos da rua", publicada originalmente em 1994, uma relação intertextual. Pepetela recupera a história narrada nos anos 90 e a desenvolve em forma romanesca, acrescentando uma segunda parte à narrativa, o futuro daqueles meninos e meninas das ruas de Luanda. (...) Porém, achamos necessário frisar que a história narrada em 2016 envolve um deslocamento na representação cultural inicial, da crônica, a partir do acréscimo de um futuro à infância retratada, futuro este marcado por acontecimentos decorridos nos últimos vinte anos em Angola (SILVA, 2020, p. 110).

Em termos de Se o passado não tivesse asas, Sofia, a nova Himba, vai se utilizar de meios escusos para assumir a propriedade do restaurante do qual já é sócia, após o falecimento de Dona Ester, a antiga proprietária. Sofia vai subtrair os direitos de Ezequiel, o filho herdeiro, que é acometido de deficiência cognitiva.

Sofia, vítima no passado, torna-se, então, a predadora, no presente, sem escrúpulos, abusando do jovem absolutamente incapaz, pois frauda, com a ajuda de seus conhecidos da elite, documentos que lhe garantem a propriedade exclusiva do restaurante. Ela conheceu, através dos seus clientes, o diretor de uma área importante da administração e entre uma gentileza e outra conseguiu um favor: 


\begin{abstract}
Explicou a morte súbita da sócia e portanto a necessidade de mudança do nome no alvará do restaurante, uma vez que as formalidades com as Finanças estavam atrasadas, o sistema sofrendo nova atualização. Ele foi compreensivo, reconheceu as dificuldades geradas no distrito por causa das bruscas mudanças de estrutura, estamos a crescer rápido demais, não há administração que aguente, porém veio bater à porta certa, resolvo isso num instante, promessa cumprida pois deu uma instrução à secretária que foi com Sofia ajudá-la a preencher impressos, entregar no guichê correspondente e voltar com tudo pronto para o chefe assinar e carimbar de selo branco. Saiu de lá com o alvará em nome dela e o mais legalmente possível (PEPETELA, 2017, p. 310).
\end{abstract}

Era a órfã, abusando de órfão, como na praia, em 1995, quando disputavam os restos de comida e de vida, em sua luta diária pela sobrevivência. Só que agora esse combate se dá em meio à cidade, à civilização, na selva de pedra.

E se ela é a metonímia de uma Angola, representada por um ideal de sobrevivência, da nação angolana, simbolizada pelo MPLA, com todas as suas contradições, com todas as violências e violações sofridas pela população, desde o tráfico de escravos, passando pelo colonialismo, pelas lutas de libertação, pela guerra civil, então ela indica que, para sobreviver a todo esse infortúnio, é preciso ser mais forte do que o inimigo, superá-lo e só posso superá-lo se o conhecer muito bem, se me transformar nele e reunir em mim, às minhas características, as características dele para que eu possa ter uma vantagem na luta. Para vencer eu preciso ser o predador. O MPLA para vencer teve que se transformar na UNITA. Só assim foi possível eliminar esta oposição armada, em 2002 e pôr fim à guerra civil.

Em relação à interpretação do texto em si, em Se o passado não tivesse asas podemos estabelecer uma comparação com Lueji, o nascimento de um império (1989), outro livro de Pepetela. Neste segundo livro, a narração oscila a entre a história da rainha e da bailarina Lu. Para efeito de nosso objetivo aqui, focamos apenas na rainha da Lunda. Lueji recebe o lukano - símbolo do poder real na Lunda - e se torna a rainha. No entanto, Tchinguri, seu irmão mais velho, não aceita o fato de ter sido preterido na sucessão real, já que ele como primogênito era o herdeiro do trono, o portador das miluínas. Seu temperamento irascível associado a um desprezo pela tradição o põem em choque com o Conselho dos Tubungo. Tchinguri perde a possibilidade de suceder Kondi quando, após um dia de bebedeira, junto ao seu irmão Chinyama, invade os aposentos do velho rei e acaba ferindo-o mortalmente. Perdido o direito ao trono, resta-lhe fazer a guerra à sua irmã mais nova e conquistar o poder, através da guerra. 
Lueji, apesar de inexperiente, mostra-se uma estrategista muito perspicaz. E acho que esse é um dos pontos altos do livro pra mim: acompanhar o percurso de construção do império a partir das ações da rainha, enquanto se prepara para o confronto com Tchinguri. Por razões de defesa, ela muda a capital, a Mussumba, para outro local, mais próxima da sede da sua linhagem. Os Lunda possuem linhagens matrilineares (o que é uma característica bantu), enquanto o poder político é passado de forma patrilinear. A linhagem de Lueji é diferente da do seu irmão Tchinguri. Ela inicialmente, recebe o apoio dos mais velhos que acham que podem controlar a jovem rainha, mas aos poucos ela vai dominando um por um e mostrando o seu valor. Como o caso do velho Kandala que falava com os espíritos, através do ngombo. O velho adivinho acaba tendo um infarto ao que tudo indica quando a rainha lhe comunica a intenção de se casar com um estrangeiro, o príncipe exilado luba, llunga, que lhe possibilitou acesso à nova tecnologia para tornar suas flechas mais fortes e resistentes. Também com as mahambas: os assentamentos dos espíritos dos ancestrais, as quais ela as coloca aos seus cuidados, de forma que para visitá-las os Tubungo tinham que lhe pedir autorização. Fortalece o seu poder central enquanto enfraquece os Tubungo, os mwata.

Até que Lueji compreende qual será a estratégia de Tchinguri que atacará primeiro todas as terras dos Tubungo, isolando a Mussumba, tentando cortar-lhe as provisões. Ninguém acredita que Tchinguri fará como disse a rainha, mas é justamente o que ele faz. Entretanto, quando seu exército está às portas da Mussumba, ela pede para conversar com Tchinguri. A conferência é aberta e ela executa o seu blefe perfeito dizendo que tinha a aliança com os Luba e para provar apresenta-lhe a nova tecnologia das flechas mais duras e resistentes do que as dos Lunda, além do pequeno grupo que acompanhava Ilunga. Lueji, então, propõe a Tchinguri que selem a paz e ele dê meia volta com seu exército, o que ele faz, deixando patente a vitória da rainha sem derramamento de sangue.

É como se Pepetela tivesse uma bola de cristal e estivesse antecipando o que aconteceria em Angola em 31 de maio de 1991, depois de um ano de negociações, quando o MPLA e a UNITA assinaram os Acordos de Bicesse, em Estoril, Portugal; na esteira da queda do muro de Berlim (1989) e da abertura da União Soviética, através da Perestroika e da Glasnost, empreendidas por Mikhail Gorbachev. Os acordos foram assinados por José Eduardo dos Santos, representando o Governo de Luanda do MPLA e Jonas Savimbi, da UNITA e tiveram a mediação de Portugal, Estados Unidos 
e da Federação Russa (não mais a URSS). Determinavam que deveria haver eleições livres em Angola dali a dezesseis meses para presidente e para os representantes da Assembleia Nacional. E o exército deveria ser unificado, o que só começou a ocorrer em 1994, após os Protocolos de Lusaka. Também a economia deixou de ser socialista e passou a ser capitalista, com a adoção da democracia liberal. Mas fato é que a UNITA não reconhecendo a vitória do MPLA nas eleições presidenciais de 1992 , alegou que as mesmas foram fraudulentas, mesmo com o acompanhamento da ONU e voltou a pegar em armas e a guerra civil recomeçou.

Em Se o passado não tivesse asas, o Outro é Ezequiel, mas quem se torna o predador, o bárbaro é Sofia. Para se ter sucesso e vencer nesta nova sociedade capitalista, neoliberal, de culto ao mercado é preciso ser o predador e sendo o predador, estar-se-á sendo bárbaro. O destino de Ezequiel é um quarto numa clínica, uma cama, onde não vão lhe faltar nenhuma das suas necessidades. A semelhança com uma prisão é enorme.

Se compararmos os dois livros, onde o Outro, em Lueji, é Tchinguri com quem se deve celebrar a paz, porque é nosso irmão. Em Se o passado não tivesse asas, o Outro, Ezequiel, é alguém que deve ser afastado, trancado, preso, eliminado. Não é mais o nosso irmão, mas realmente alguém diferente e que nos atrapalha. Se Tchinguri e Ezequiel nos dois livros representam a UNITA, podemos observar a mudança de enfoque, em 1989 e em 2016. É evidente que Se o passado não tivesse asas foi escrito após os Acordos de Luema de 2002 que garantiram o processo de paz, e após o assassinato do líder da UNITA, Jonas Savimbi. Mas acho que representam uma possibilidade de entendimento do que a UNITA que ainda estava em guerra passou a representar naquela época para os angolanos de uma forma geral: o inimigo que deveria ser igualado e depois eliminado.

\section{Referências Bibliográficas}

ABDALA JR., Benjamin. Fronteiras e identidades no plural: das demarcações políticas aos comunitarismos supranacionais. In SILVA, Renata Flavia da (Org.). Utopias comuns em múltiplas fronteiras. Ensaios sobre literaturas africanas de língua portuguesa. Niterói: Eduff. 2017. 
APPIAH, Kwane Anthony. Na casa de meu pai. Tradução por Vera Ribeiro. $4^{a}$ reimpressão. Rio de Janeiro: Contraponto editora, 2014.

BENJAMIN, Walter. Origem do drama trágico alemão. Tradução por João Barrento. $2^{\mathrm{a}}$ edição. $1^{\text {a }}$ reimpressão. São Paulo: Autêntica Editora, 2016.

. O anjo da história. Tradução por João Barrento. $2^{\mathrm{a}}$ edição. $2^{\mathrm{a}}$ reimpressão. São Paulo: Autêntica Editora, 2018.

DIDI-HUBERMAN, Georges. Diante do tempo. História da arte e anacronismo das imagens. Tradução por Vera Casa Nova e Márcia Arbex. $2^{\mathrm{a}}$ reimpressão. Belo Horizonte: Editora UFMG, 2019.

FOURSHEY, Catherine C. GONZALES, Rhonda M. SAIDI, Christine. África Bantu: de 3500 a.C. até o presente. Tradução por Beatriz Silveira Castro Filgueiras. Petrópolis: Editora Vozes, 2019.

GAGNEBIN, Jeanne Marie. História e narração em Walter Benjamin. $2^{\mathrm{a}}$ edição. $5^{\mathrm{a}}$ reimpressão. São Paulo: Editora Perspectiva, 2013.

HALL, Stuart. A questão multicultural. In Sovik, Liv (Org.). Da diáspora: Identidades e mediações culturais. $2^{a}$ ed. Tradução por Adelaide G. Resende et al. Belo Horizonte: Editora UFMG. 2018.

LÖWY, Michael. Walter Benjamin: aviso de incêndio. Uma leitura das teses "Sobre o conceito de história". Tradução por Wanda Nogueira Caldeira Brant. Tradução das teses: Jeanne Marie Gagnebin e Marcos Lutz Müller. 4ª reimpressão. São Paulo: Boitempo Editorial, 2020.

MATA, Inocência. Pepetela: um escritor (ainda) em busca da utopia. Literatura Scripta. Revista do Programa de Pós-Graduação em Letras e do Centro de Estudos Luso-Afro-brasileiros da PUC-Minas. Belo Horizonte: v. 3. N. 5, p. 243-259, $2^{\circ}$ sem de 1999. Disponível em: [http://periodicos.pucminas.br/index.php/scripta/article/view/10318]. Acessado em 08 de outubro de 2020. Edições Colibri, 2010.

Ficção e História na Literatura Angolana: O caso de Pepetela. Lisboa:

MILLER, Joseph C. Poder político e parentesco: os antigos estados Mbundu em Angola. Tradução por Maria da Conceição Neto. Luanda, Arquivo Histórico Nacional, 1995.

PEPETELA. A parábola do cágado velho. Lisboa: Publicações Dom Quixote, 1996.

. Predadores. Rio de Janeiro: Língua Geral, 2007.

. O planalto e a estepe. São Paulo: Leya Editora, 2009.

. Crônicas com fundo de guerra. Lisboa: Edições Nélson de Mattos, 2011.

As aventuras de Ngunga. Lisboa: Publicação Dom Quixote, 2014.

Lueji. O nascimento de um império. São Paulo: Leya Editora, 2015.

Se o passado não tivesse asas. São Paulo: Leya, 2017. 

. O cão e os caluandas. São Paulo: Editora Kaluanda, 2019.

ROTHWELL, Phillip. Pepetela: o cronista pós-comunista do MPLA. In PAZOS-ALONZO, Cláudia et al. (Ed.). De oriente a ocidente: estudos da Associação Internacional de Lusitanistas. Volume III. Estudos da AIL sobre África. p. 199-213. Março de 2019. Disponível em: [https:/l lusitanistasail.press/index.php/ailpress/catalog/book/165]. Acessado em 30 de setembro de 2019.

SILVA, Renata Flávia da. Meninos da rua: Pepetela e a reescritura do passado. In PAZOSALONZO, Cláudia et al.(Ed.) De Oriente a Ocidente: estudos da Associação Internacional de Lusitanistas: Volume III. Estudos da AlL sobre África. p.215-228. 2019. Disponível em: [https://lusitanistasail.press/index.php/ailpress/catalog/book/165]. Acessado em 30 de setembro de 2019.

SILVA, Renata Flávia da. Amílcar Cabral e Pepetela: processos intertextuais a propósito do Homem Novo. In Lusotopie. Volume 19. Issue 1. 2020. Disponível em: [https://brill.com/view/journals/luso/19/1/article-p101_6.xml]. Acessado em 24 de outubro de 2020. p. 101-114. 